\title{
Modelling Desert Dune Fields Based on Discrete Dynamics
}

\author{
STEVEN R. BISHOP ${ }^{\mathrm{a}, *}$, HIROSHI MOMIJI ${ }^{\mathrm{b}}$, RICARDO CARRETERO-GONZÁLEZ $^{\mathrm{a}} \uparrow$ and ANDREW WARREN ${ }^{\mathrm{b}}$ \\ ${ }^{\mathrm{a}}$ Centre for Nonlinear Dynamics and its Applications, University College London, Gower Street, London WC1E 6BT, UK; ${ }^{\mathrm{b}}$ Department of Geography, \\ University College London, 26 Bedford Way, London, WC1H OAP, UK
}

(Received 10 May 2001)

\begin{abstract}
A mathematical formulation is developed to model the dynamics of sand dunes. The physical processes display strong non-linearity that has been taken into account in the model. When assessing the success of such a model in capturing physical features we monitor morphology, dune growth, dune migration and spatial patterns within a dune field. Following recent advances, the proposed model is based on a discrete lattice dynamics approach with new features taken into account which reflect physically observed mechanisms.
\end{abstract}

Keywords: Desert dune field; Modelling; Discrete dynamics; Lattice; Non-linearity

\section{INTRODUCTION}

Mathematical modelling is now a common tool in many fields of study. In some areas reconstruction techniques are used to develop a model from known data to improve our understanding of physical interactions, while others employ models to predict future states, for example, possible hazards. In the geoscientific field, the usefulness of mathematical modelling has been widely recognised through its applications to such topics as hill slope evolution, river morphology and sea level change (see for example Woldenberg (1985) and Anderson (1988)). Here we are interested in the morphology, dune growth, downwind migration and spatial patterns which form in a sand field, where we aim to qualitatively and quantitatively mimic real dunes and also to identify the physical features which play the most important role.

Dune fields show fascinating features which attract the research attention of many scientists. For geographers a dune field is of prominent interest since it is a typical landform where aeolian processes dominate. Such aeolian landforms are estimated to cover about one-fourth of the earth surface (Livingstone and Warren, 1996 p1). Furthermore, dune fields are also found on Mars (Greeley and Iversen, 1985 and Edgett and Malin, 2000) and Venus (Greeley et al., 1992). For physicists the dynamic, selforganised patterns in which we can see, for example, regular spacing with embedded defects, are very attractive. In terms of physics, a dune field is a typical non-linear open system (for an introductory review of this viewpoint see Werner (1999)). While in engineering, a knowledge of the formation of dune fields is still important today because we are now hoping to exploit these vast areas of land for example by introducing networks of roads and pipelines.

Although vegetation and pre-existing topography play significant roles in dune formation in some areas (see for example Cooke et al. (1993)), we simplify the problem here by restricting our attention to dunes in a perfectly dry and initially almost flat desert. These dunes are called free dunes. In such a dune field, any landform is a result of recurring interaction between wind flow over the dune field, topography, and gravity. Despite much field work (for example Kocurek et al. (1992)), only a few modelling attempts have succeeded even in reproducing a single dune.

A typical dune field extends for hundreds of kilometres, and takes many thousands of years to form, so that the study of dune-scale geomorphology cannot rely on well defined experiments. The alternative is to assume a set of plausible physical processes based on observations, create a model, and then compare simulated results to nature.

Analytical results are typically not available. Difficulties arise due to the strong non-linearity involved in the system, which includes wind flow over a dune field expressed by the Navier-Stokes equation, sand transport

*Corresponding author. Tel.: +44-020-7679-7729. Fax: +44-020-7380-0986. E-mail: s.bishop@ucl.ac.uk

${ }^{\dagger}$ Department of Mathematics and Statistics, Simon Fraser University, Burnaby, BC, V5A 1S6, CANADA 
(a) Dome dune

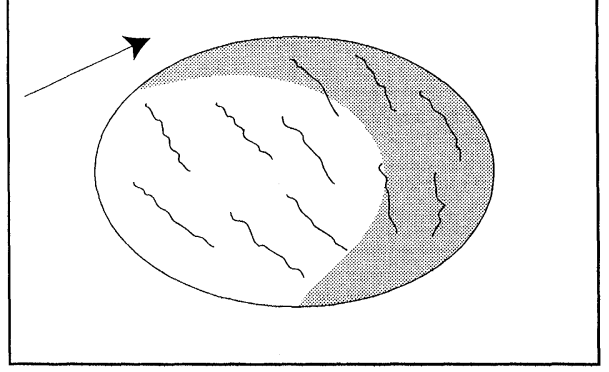

(c) Transverse dune

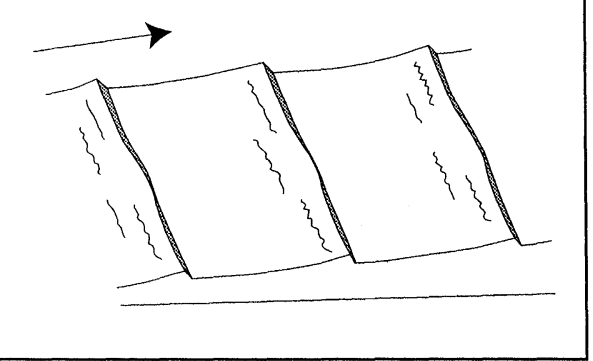

(e) Star dune

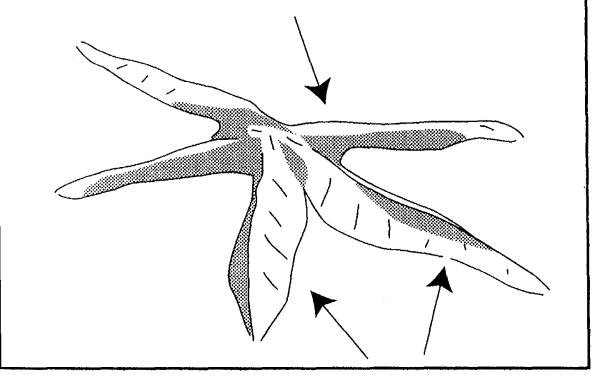

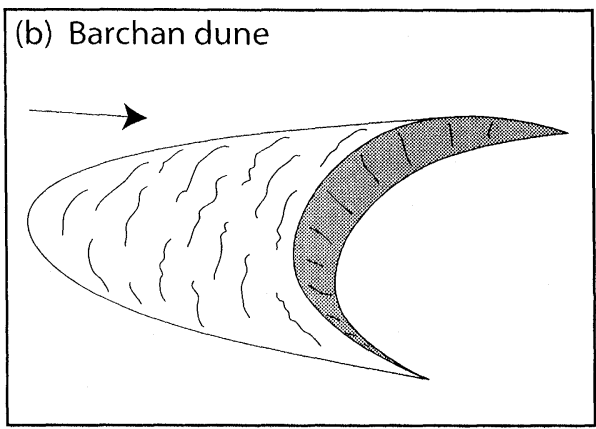

(d) Linear dune
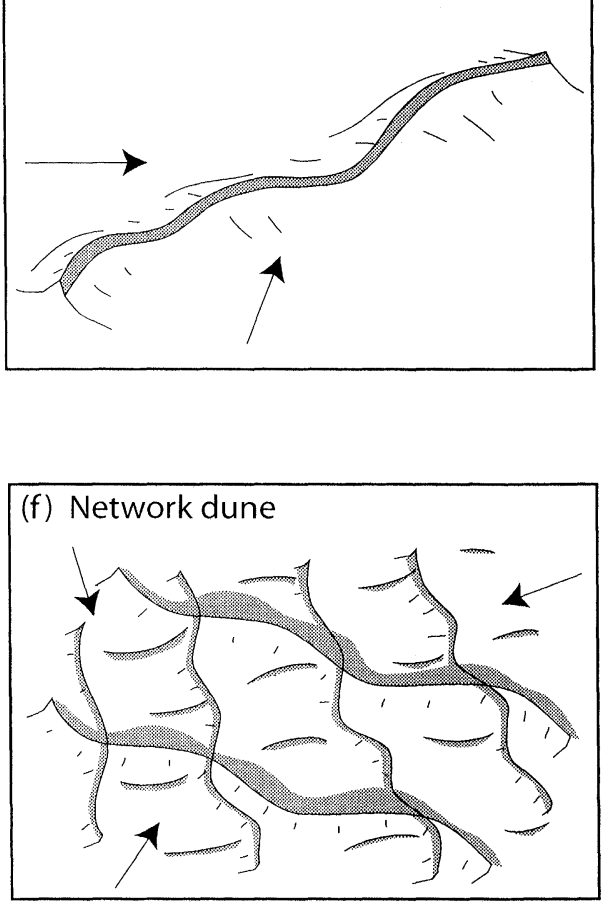

FIGURE 1 Schematic views of typical dunes: (a) dome dune, (b) barchan dune, (c) transverse dune, (d) linear dune, (e) star dune and (f) network dune. ((a)-(e) after McKee, 1979; (f) after Cooke et al., 1993). Arrows show the predominant wind directions.

induced by wind and sudden deformation by gravity known as avalanching, the latter leading to non-smooth dynamics. Since the work of Bak et al. (1987), avalanching has been intensively studied in relation to Self-Organised Criticality (SOC) (Bak, 1996). Yet, some characteristic features of dunes, such as strong asymmetric profile, need theory which goes beyond linear analysis.

To describe the evolution of such a system starting from first principles we have to consider momentum conservation of the system comprised of air and sand grains. However no such equation is yet available. Even if we can consider wind flow and sand transport separately, it is extremely difficult to solve the Navier-Stokes equation, even in the case of an isolated single dune on a flat surface (Howard and Walmsley, 1985; Wippermann and Gross, 1985; Zeman and Jensen, 1988; Weng et al., 1991; Stam, 1997; van Dijk et al., 1999). In the case of a dune field comprising many dunes with different shapes, it is almost impossible to calculate the wind flow with the same accuracy as in the case of a single dune. Furthermore, we have to solve these equations under moving boundary conditions as dunes grow, in a three-dimensional space $(x, y, z)$.

Tracking dune evolution by calculating wind flow over a dune field each time is therefore practically impossible. To simulate dune fields, our approach is through phenomenological models based not on detailed physical processes, but on simplified rules which, nevertheless correctly reflect observations.

Significant progress has been made by the introduction of two models by Nishimori and Duchi (1993), Nishimori et al. (1998), and Werner (1995) (also see Momiji et al., 2000 for a review). They both assume that a dune field can be considered as an accumulation of sand "slabs" (artificially introduced sand blocks) piled in a twodimensional horizontal lattice, and that the movement of 
these slabs can be used to simulate wind directional sand transport and deformational shaping by gravity. These can be considered to be the minimal model for describing a dune field. A similar model for a coastal dune field comprising alternating sequences of dunes and vegetation covered areas was developed by de Castro (1995).

Both Nishimori's and Werner's models succeeded in reproducing some types of dunes, and explaining the relation between dune shape and its formative environment. Incorporating other plausible physical mechanisms into these minimal models one by one, and comparing results with observations, it is thought to be possible to clarify the physical processes involved in a dune field system, and to develop a more general model that resembles processes in nature. Unlike Nishimori's model, Werner's model takes into account the time scale difference between bulk sand transport and avalanching.

In this paper, to aid the reader, dunes and dune field geomorphology and related aeolian processes are briefly reviewed. A model is proposed which extends Werner's work, introducing physically motivated modifications making the model results more realistic.

\section{DUNE FIELD GEOMORPHOLOGY AND AEOLIAN PROCESSES}

\section{Classification of Simple (elementary) Dunes}

Despite the complexity of wind patterns in nature there are some recurring features of dune fields that are found in many different desert regions. Free dunes can be classified into three basic groups, depending on the alignments of their crest to the net sand transport, namely transverse, linear and star dunes. Net sand transport is normal to the crests for transverse dunes, parallel to the crests for linear dunes, and towards a central node for star dunes. Within each of these three categories there can be further subdivisions.

\section{Transverse Dunes}

Dome dune: an isolated, usually transverse dune with no slip face (Fig. 1(a)).

Barchan dune: a free transverse dune with a crescentic plan-shape in which the crescent opens downwind (Fig. $1(b))$.

Transverse dune: dune ridges with crests transverse to the dominant wind, which migrate, for the most part, in the direction of the dominant wind (Fig. 1(c)).

Reversing dunes: transverse dunes that reverse in the direction as the wind changes through $180^{\circ}$.

\section{Linear Dunes (Fig. 1(d))}

Seif dune: a sinuous, sharp-crested, linear dune. Sand ridge: partly vegetated linear dune, usually large than a seif.

\section{Star Dunes}

Star dune: a large pyramidal or dome-like dune with arms (Fig. 1(e)).

Network dune: result of the overlap of a number of transverse dune systems, each aligned to a different wind in a complex annual regime (Fig. 1(f)).

\section{Dune Dynamics by Wind and by Gravity}

Wind flow over a terrain can be characterised by the wind shear velocity $\left(u_{*}\right)$. An increase in shear velocity against distance is observed in field experiments for the windward slope of barchan dunes and of transverse dunes (see for example Lancaster et al. (1996) and Frank and Kocurek (1996b)). The wind flow pattern over an isolated gentle hill surrounded by a plane surface is predicted by the Jackson-Hunt theory (Jackson and Hunt, 1975). This theory's most important result is that there is an increase in shear velocity over the windward slope and a decline over the leeward slope. However the applicability of this theory is limited. For example it cannot predict the reverse flow in the lee of the slip face.

Sand motion is triggered and maintained by wind shear stress working on the sand surface. The dominating mode of sand transport for dune dynamics is a ballistic sand grain motion called saltation, where the typical leap is order of centimetres. In saltation-dominated sand transport, the sand flux $(q)$ is approximately proportional to the cube of the wind shear velocity $\left(u_{*}^{3}\right)$ (Bagnold, 1941). In the lee of the dune, avalanching occurs when the slope exceeds a certain angle, typically taken as $33^{\circ}$ for dry sand. This sand transport induced by gravity forms a slip face with a straight cross section. Theory and laboratory experiments suggest that this slip face is indeed not a smooth but a complicated surface, which is a consequence of avalanches of all sizes (Bak et al., 1987; Bak, 1996). If the sand is wet, coherent slumping occurs, where a large area of the slip face surface slides down simultaneously (Cooke et al., 1993 Figure 23.22).

Transverse dunes and barchan dunes are known to migrate downwind $(+x$ direction, say) without changing their shape. Field data show that the lower the dune, the quicker it migrates (a summary can be found in Cooke et al. (1993) Figure 23.24). This inverse relation between dune migration speed $\left(c_{\mathrm{d}}\right)$ and dune height $(H)$ was examined using a dune field model by Nishimori et al. (1998), and has been theoretically derived by Momiji and Warren (2000).

\section{Forming Environment of Each Type of Dune}

The particular dune type which forms in any particular vegetation-free environment is primarily determined by the wind regime. Fryberger (1979) categorised annual wind patterns into three main regimes; "unimodal", "bimodal" and "complex". In "unimodal" regimes winds blow from almost the same direction throughout the year 


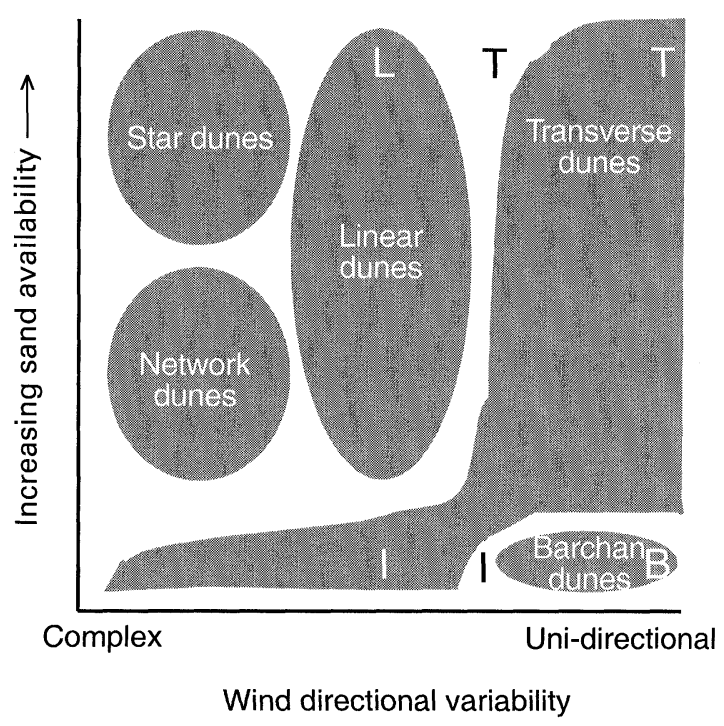

FIGURE 2 Dune type diagram with regard to sand availability and wind direction variability (after Livingstone and Warren (1996) Figure 5.22). "B", "I", "L" and "T" denote respective barchan dunes, isolated dunes linear dunes and transverse dunes, which are simulated in this study.

In "bimodal" regimes the seasonal wind distribution comprises two directions or modes. In "complex" regimes the wind distribution comprises either more than two modes or no distinct mode. A relation between bedform alignment and directionally varying flows was proposed by Rubin and Hunter (1987). They speculated that bedforms are aligned such that the gross normal sand transport throughout the cycle of wind variation is maximum. This relation was supported with field observations of aeolian dunes by Lancaster (1991).

The second important factor in determining the dune type is the amount of sand available for dune building. Wasson and Hyde (1983) developed a diagram of dune types with respect to wind variability and sand availability. Later this diagram was refined by Livingstone and Warren (1996 Figure 5.22), schematically reproduced here as Fig. 2 in this paper. The classifications contained in this diagram are on the whole accepted by many researchers.

\section{MATHEMATICAL MODELLING OF A DUNE FIELD}

To model the formation and migration of free dunes we consider a model based on a discrete three-dimensional space. Consider a two-dimensional lattice labelled $(i, j)$ (Fig. 3(a)); dune height is measured obliquely out of the page. This portion of space is assumed to be a typical section within a dune field.

To achieve good results using modest computational time we use simplified algorithms to monitor state space variations. Here we assume that the dune field consists of three-dimensionally discrete sand slabs (Fig. 3(a)). Consequently the height $(\eta(i, j))$ is discrete and proportional to the number of sand slabs piled on each lattice site $(h(i, j))$ :

$$
\eta(i, j)=h(i, j) / 3
$$

where $1 / 3$ is slab aspect ratio. Periodic boundary conditions are adopted so that the small simulated area may be repeatedly copied to represent the whole dune field like a mosaic.

The first step in the algorithm is to randomly choose a site $(i, j)$, from which a single slab is considered to be eroded and then transported downwind in the $+x$ direction. The distance moved is a specific number of lattice sites $L(i, j) . L(i, j)$ is a site-dependent, rounded-down integer, whose definition is given below. The transported slab is then deposited on top of the slab pile at the new site $(i+L(i$, $j), j$ ) with a probability $(P)$. If the slab is not deposited at this site, it is transported farther (bouncing) to the site $(i+L(i, j)+L(i+L(i, j), j), j)$, and is deposited again with a certain probability. This procedure continues until the slab is eventually deposited at a site. Based on Bagnold's observation that saltating sand grains are more likely to bounce on a stony surface than on a sandy surface (Bagnold, $1941 \mathrm{pp} 36-37$ ), the deposition probability at sites with at least one slab is set higher $\left(P_{\mathrm{s}}=0.6\right)$ than the probability at sites without a slab $\left(P_{\mathrm{ns}}=0.4\right)$. Furthermore, the concept of a shadow or lee zone downwind of dunes is introduced (Fig. 3(b)), in which no erosion occurs and the deposition probability is unity at any site within the lee zone, i.e. $P_{\mathrm{s}}=P_{\mathrm{ns}}=1.0$. This shadow zone is taken as $15^{\circ}$ from the dune crest, corresponding to the reattachment point downwind which is roughly four times as long as the dune height from the dune (Frank and Kocurek, 1996a). Together with this wind-directional transport, avalanching occurs at the place of the steepest descent if the number of slabs between any neighbouring sites differs by three, which is equivalent to the angle of repose of $33.7^{\circ}$ for the nearest neighbouring sites and $25.2^{\circ}$ for the second nearest, respectively (Fig. 3(c)).

The increase in shear velocity over a dune can be formulated by adding terms to the original transport length, which are related to the surface height:

$$
L(i, j)=\left\{\begin{array}{ll}
L_{0}+C_{1}\left(h(i, j)-h_{\mathrm{ref}}\right)+C_{2}\left(h(i, j)-h_{\mathrm{ref}}\right)^{2} & \left(h(i, j) \geq h_{\mathrm{ref}}\right) \\
L_{0}+C_{1}\left(h(i, j)-h_{\mathrm{ref}}\right) & \left(h(i, j)<h_{\mathrm{ref}}\right)
\end{array},\right.
$$

where $L_{0}, C_{1}$ and $C_{2}$ are constants, $(i, j)$ is the erosion/ongoing "bounce" site and $h_{\text {ref }}$ is the reference number of slabs. The linear term $C_{1}$ in Eq. (1) controls the windward surface slope and produces an asymmetric dune profile as in nature, whereas the non-linear term regulates dune height (Momiji et al., 2000. The reference number of slabs $\left(h_{\text {ref }}\right)$ is defined here as

$$
h_{\mathrm{ref}}(t)=h_{\mathrm{avg}}-\frac{1}{2 L_{\mathrm{s}}^{2}} \sum_{(i, j)=(0,0)}^{\left(L_{\mathrm{s}}-1, L_{\mathrm{s}}-1\right)}\left|h(i, j ; t)-h_{\mathrm{avg}}\right|
$$


(a)
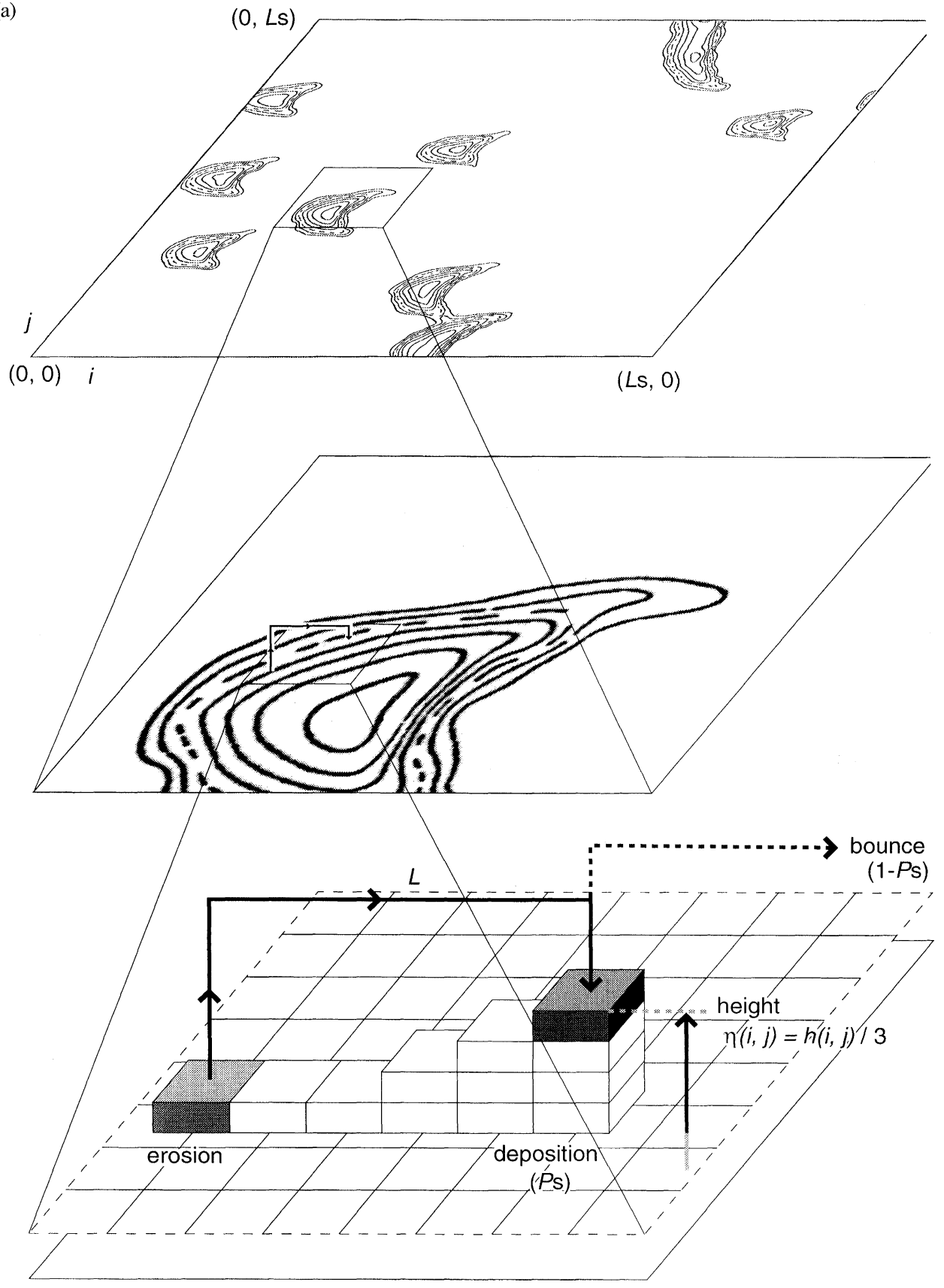

$h(i, j)$ : number of slabs at site $(i, j)$

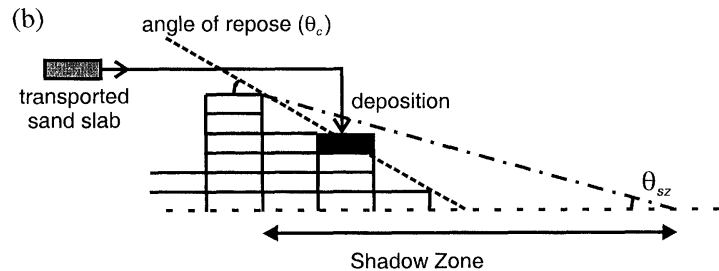

where $L_{\mathrm{S}} \times L_{\mathrm{S}}$, is the lattice size. The second term of the right-hand side of this equation expresses how many slabs at a site on average incorporate dunes construction both erosionally and depositionally. In the simulation time denoted by $t$ is the number of lattice sites that have been polled for slab erosion divided by the number of surface lattice sites $\left(L_{\mathrm{s}} \times L_{\mathrm{s}}\right)$.

Figure 4 shows how the lattice is adjusted to model a dune field with bi- or multi-directional wind. When the wind is initially blowing parallel to the $i$ axis, and then 


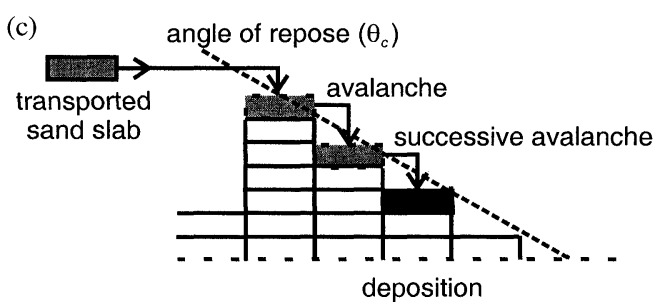

\begin{tabular}{|c|c|c|}
\hline NN & N & NN \\
102 & 101 & 100 \\
\hline$N$ & & $N$ \\
102 & & 98 \\
\hline$N N$ & $N$ & $N N$ \\
101 & 100 & 99 \\
\hline
\end{tabular}

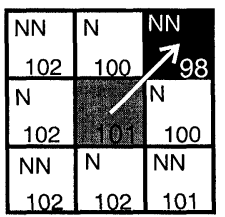

$\mathrm{N}$ : Nearest neighbouring sites NN: 2nd Nearest neigbouring sites

\section{in the steepest direction}

FIGURE 3 Lattice model configuration and algorithms: (a) winddirectional sand transport, (b) shadow zone and (c) avalanching. In the shadow zone no erosion occurs and the deposition probability is 1.0 .

changes its direction with angle of $\theta$ from $i$ axis, the lattice is rotated by an angle $\theta$ keeping the topography unchanged:

$$
\begin{gathered}
i=\left(i_{\text {new }}-L_{\mathrm{s}} / 2\right) \cos \theta-\left(j_{\text {new }}-L_{\mathrm{s}} / 2\right) \sin \theta+L_{\mathrm{s}} / 2 \\
j=\left(i_{\text {new }}-L_{\mathrm{s}} / 2\right) \sin \theta+\left(j_{\text {new }}-L_{\mathrm{s}} / 2\right) \cos \theta+L_{\mathrm{s}} / 2 \\
h\left(i_{\text {new }}, j_{\text {new }}\right)=h(i, j) .
\end{gathered}
$$

Consequently, the wind always blows parallel to the $i$ axis. After the rotation, we check whether any neighbouring sites break the angle-of-repose criterion. The drawback of this scheme is that the number of slabs is not conserved. If the average number of slabs $\left(h_{\mathrm{avg}}\right)$ is small, the situation is worse. In the case of $h_{\text {avg }}=2.0$ the difference between the initial and the final numbers of slabs after $t=1500$ is about $10 \%$. However, if we choose

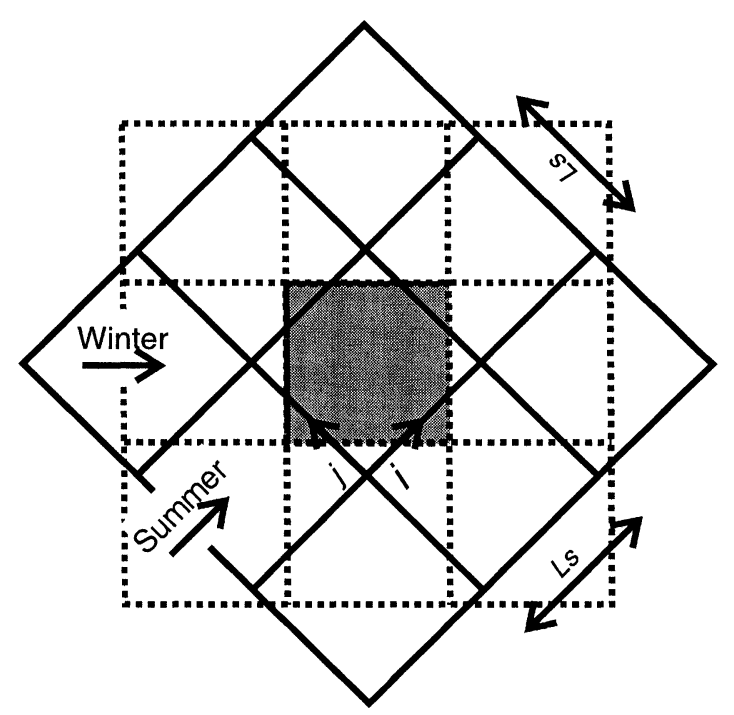

FIGURE 4 Modelling scheme for a dune field where the wind changes direction. The lattice is rotated in response to the wind directional change. After the rotation, neighbouring sites are checked to see if they break the angle-of-repose criterion.

an optimal rotation (pivot) centre for each wind-direction change, which is usually different from $\left(L_{\mathrm{s}} / 2, L_{\mathrm{s}} / 2\right)$, such a difference in number of slabs can be reduced to the order of $0.1 \%$ with modest additional computational time. This is a practical remedy. An ideal solution is to use an infinitely large lattice (i.e. $L_{\mathrm{s}} \rightarrow+\infty$ ) to increase uniformity in spatial distribution of dunes.

\section{SIMULATION RESULTS AND DISCUSSION}

\section{Pattern and Sand Availability}

Table I shows parameters used in the simulations that follow. In the model, sand availability is defined as the average number of slabs per site $\left(h_{\text {avg }}\right)$ taken over all sites. In Fig. 5 we show the results of a simulation of $t=1500$

TABLE I Simulation parameters

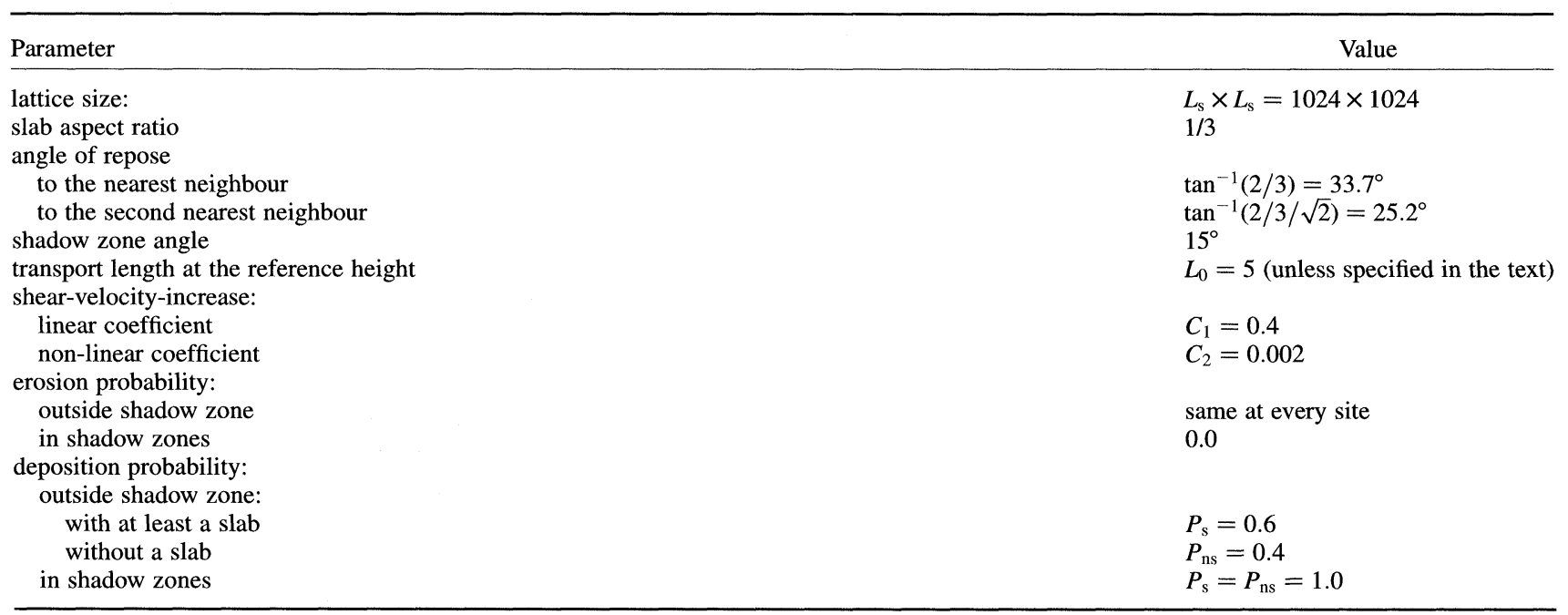




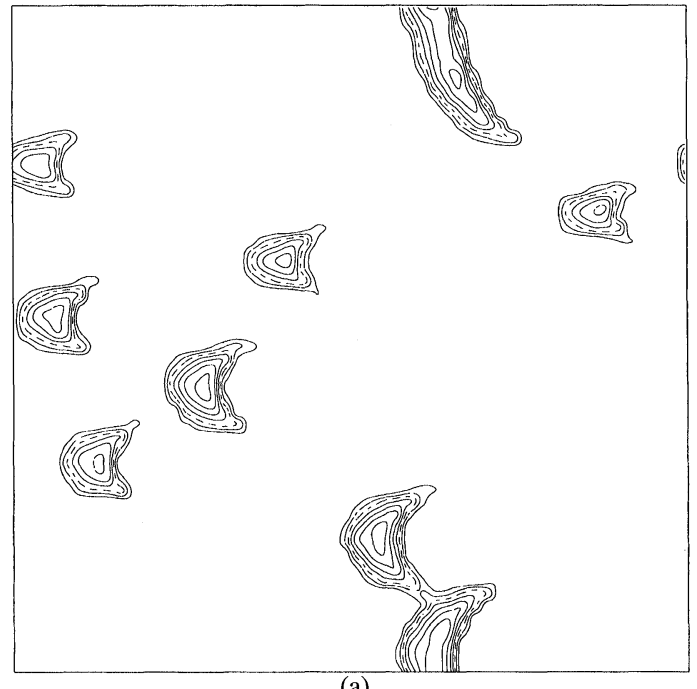

(a)

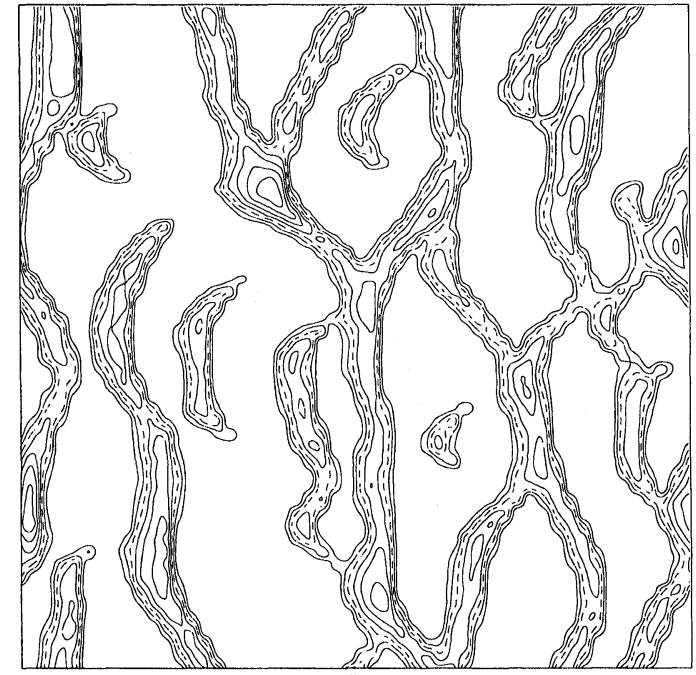

(b)

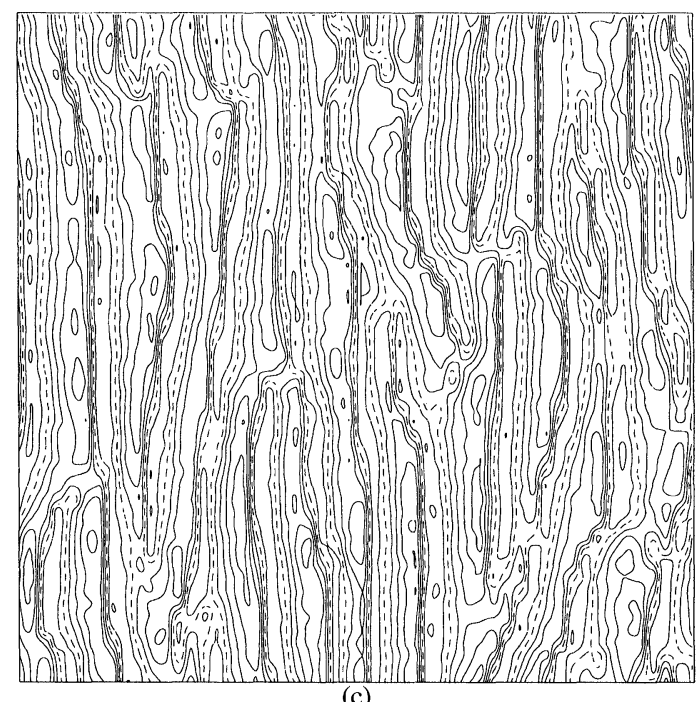

(c)

FIGURE 5 Different types of dune simulated with various sand availabilities $\left(h_{\text {avg }}\right.$ ); (a) 2.0, (b) 7.0 and (c) 20.0. All simulations started with an almost flat surface. The contour interval is $h=5$.

beginning with an almost flat surface. As $h_{\text {avg }}$ increases, the dune field changes from no pattern $\left(h_{\text {avg }} \leq 1.1\right)$ to barchan dunes shown in Fig. 5(a) for $h_{\text {avg }}=2.0$, then to laterally connected barchan dunes (Fig. 5(b), $h_{\text {avg }}=7.0$ ), and finally to transverse dunes (Fig. 5(c), $h_{\text {avg }}=20.0$ ). The laterally connected barchan dunes are more sinuous than the transverse dunes formed in an infinitely deep sand field. The change from barchan dunes to transverse dunes in response to the increase of sand availability coincides with field observations (Livingstone and Warren 1996 Figure 5 22, Fig. 2 in this paper).

Characteristics of each pattern can be extracted through the Fourier transform $(h(i, j) \rightarrow \hat{h}(i, j))$. The Fourier components which are not thought to contribute to the pattern $\hat{h}(0, j)$ and $\hat{h}(i, 0)$ are all excluded. As sand availability increases, the wavelength in the $i$ direction decreases. For an infinitely deep sand field, the first peak is 78.8, and the second is 102.4 . Transverse dune systems formed in an infinitely deep sand field are more regular than that with inter-dune bare surfaces. The intensity ratio of the first peak to the second peak is higher when $h_{\text {avg }} \geq$ 20.0 than when $h_{\text {avg }}=10.0$.

There is a sudden transition from no pattern to a pattern of isolated dunes without distinct asymmetry or a slip face, namely dome dunes. This transition was checked by using 15 different sets of simulations. Table II shows the resulting maximum number of slabs $\left(h_{\max }\right)$, for sand availability $\left(h_{\text {avg }}\right)$ values of 1.1 and 1.2. In all simulations with an average number of slabs per site $\left(h_{\text {avg }}\right)$ of 1.1 , no pattern was formed, whereas for $h_{\text {avg }}$ of 1.2 , isolated dunes formed in all simulations. The threshold thus lies between $h_{\text {avg }}$ of 1.1 and 1.2. As sand availability increases further to $h_{\text {avg }}=2.0$, these dome dunes gradually change to barchan dunes.

If, rather than starting with an almost flat surface, we start with an initial surface consisting of barchan dunes, 
TABLE II Maximum dune height when sand availabilities are below and above the threshold

\begin{tabular}{|c|c|c|c|c|c|c|c|c|c|c|c|c|c|c|c|}
\hline Simulation & 1 & 2 & 3 & 4 & 5 & 6 & 7 & 8 & 9 & 10 & 11 & 12 & 13 & 14 & 15 \\
\hline$h_{\max }\left(h_{\mathrm{avg}}=1.1\right)$ & 5 & 5 & 5 & 4 & 5 & 5 & 4 & 5 & 5 & 4 & 4 & 4 & 4 & 4 & 5 \\
\hline$h_{\max }\left(h_{\mathrm{avg}}=1.2\right)$ & 23 & 25 & 22 & 24 & 25 & 25 & 21 & 22 & 23 & 24 & 24 & 26 & 25 & 24 & 22 \\
\hline
\end{tabular}

they remain as features even when the sand availability is less than the previously determined threshold.

In the following numerical experiments, the simulation time $(t)$ is 3000 , the first half $(t \leq 1500)$ of this time being for the initial barchan dunes creation. At $t=1500$ half of the slabs at every site were removed, and then simulations were resumed. That is at $t=1500$ we reduced the barchan dunes to half their height, with a corresponding reduction in the steepness of the windward surfaces. The initial sand availability $\left(h_{\text {avg }}(t \leq 1500)\right)$ was varied from 1.2 to 2.0 . Table III shows the sand availabilities $\left(h_{\mathrm{avg}}\right)$ for $t \leq 1500$ and for $t \geq 1500$, the resulting maximum number of slabs $\left(h_{\max }\right)$ and the patterns at $t=3000$. "N" and "D" represent no pattern and the pattern with (barchan) dunes, respectively. Dunes did not disappear completely, even with the sand availability less than the threshold. However, many of these dunes are not strongly asymmetric in their wind-directional shape, and do not have distinct slip faces. In the region below the threshold, the system can be said to be bistable, i.e. both no pattern and the pattern with isolated (dome/barchan) dunes can exist, depending on the initial surface morphology. To check if there is another threshold in sand availability, below which initially placed barchan dunes disappear, more simulations are necessary.

\section{Dune Migration and Scales in the Model}

To estimate the scaling of length and time in our model we consider the downwind migration of barchan dunes. We fix the sand availability $\left(h_{\text {avg }}\right)$ at 2.0. Figure 6(a) shows a barchan dune field which appeared from an almost flat surface after $t=1500$. While Fig. 6(b) shows the field with all other dunes removed except the one marked with a $*$ in Fig. 6(a). To view migration of the complete dune field, in Fig. 6(c) we plot the field $t=100$ later, i.e. $t=$ 1600. Whereas in Fig. 6(d) we plot the corresponding migration of the isolated dune of Fig. 6(b) after a further $t=100$. From (a) and (c), the barchan dunes are found to be migrate downwind without changing their individual shapes or the alignment (the two dunes at the bottom show a partially connected transient form). This is cooperative motion, and as seen in the migration from (b) to (d), without interaction with neighbouring dunes, a barchan dune cannot maintain its shape during its downwind migration.

The dune labelled $*$ in Fig. 6 is about 30 slabs ( $=10$ l.u.; lattice units) high, and migrates about 500 l.u. in a period of $t=100$. A $10-\mathrm{m}$ barchan dune is known to migrate typically $20 \mathrm{~m}$ annually Cooke $e t$ al., 1993, Figure 23.24). Considering both these dynamics, temporal and spatial scales in the model can be estimated as follows:

$$
\begin{aligned}
& \text { 11.u. }=1 \mathrm{~m} \\
& 4 t=1 \text { year. }
\end{aligned}
$$

Table IV shows the relation between dune pattern and the slab transport length $\left(L_{0}\right)$ at the reference height. Sand availability $\left(h_{\text {avg }}\right)$ is 2.0 . When the wind is too strong $\left(L_{0}=50\right)$, an almost flat surface appears. On the other hand, when the wind is weak $\left(L_{0}=2\right)$, the dunes are low. Both these results support earlier analyses (Momiji and Warren, 2000; Momiji and Bishop, 2001). Sand flux ( $q$ ) on the level surface can be related to the slab transport length $\left(L_{0}\right)$ at the reference height as follows (Nishimori et al., 1998, Momiji et al., 2000):

$$
q=\left[L_{0}^{3} / 3\right][\gamma]\left[L_{0}\right] /[t],
$$

where $\gamma$ is the bulk sand density $\left(1961 \mathrm{~kg} \mathrm{~m}^{-3}\right)$ for quartz sand with the lowest porosity in theory $(0.26$, see for example Pye and Tsoar (1990)), which gives the highest estimation for the sand flux $(q)$. From Eqs. (2) and (3), the sand flux $(q)$ for $L_{0}=1$ is calculated as $8.3 \times$ $10^{-5} \mathrm{~kg} \mathrm{~m}^{-1} \mathrm{~s}^{-1}$, which is less than $10 \%$ of values observed for a reversing dune by Walker (1999). Table IV predicts that if the sand flux is small enough, no dunes emerge, i.e. a threshold in sand flux exists. When $L_{0}=3$ dune migration speed is about $60 \%$ of that when $L_{0}=5$.

\section{Patterns in a bi-directional Wind Regime}

Once we know the time scale in the model, we can simulate a dune field in which the wind direction changes seasonally, a common situation in nature. Figure 7 shows

TABLE III Conservation of the initial dune pattern below the threshold in sand availability ("N" and "D" represent no pattern and the pattern with (barchan) dunes, respectively)

\begin{tabular}{lccccccccc}
\hline$h_{\text {avg }}(t \leq 1500)$ & 1.2 & 1.3 & 1.4 & 1.5 & 1.6 & 1.7 & 1.8 & 1.9 & 2.0 \\
\hline$h_{\text {avg }}(t \geq 1500)$ & 0.43 & 0.59 & 0.65 & 0.70 & 0.75 & 0.79 & 0.82 & 0.75 \\
$h_{\max }$ & 3 & 19 & 21 & 23 & 23 & 25 & 27 & 24 & 27 \\
pattern & $\mathrm{N}$ & $\mathrm{D}$ & $\mathrm{D}$ & $\mathrm{D}$ & $\mathrm{D}$ & $\mathrm{D}$ & $\mathrm{D}$ & $\mathrm{D}$ & $\mathrm{D}$ \\
\hline
\end{tabular}




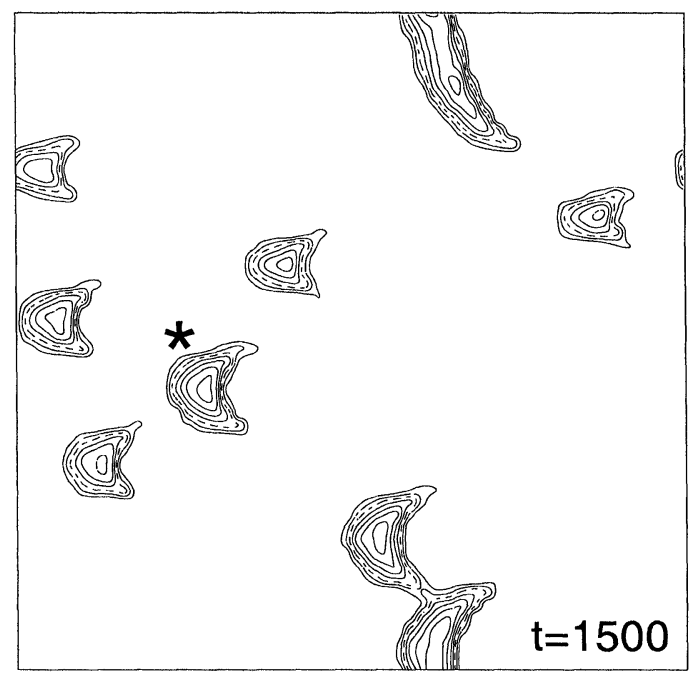

(a)

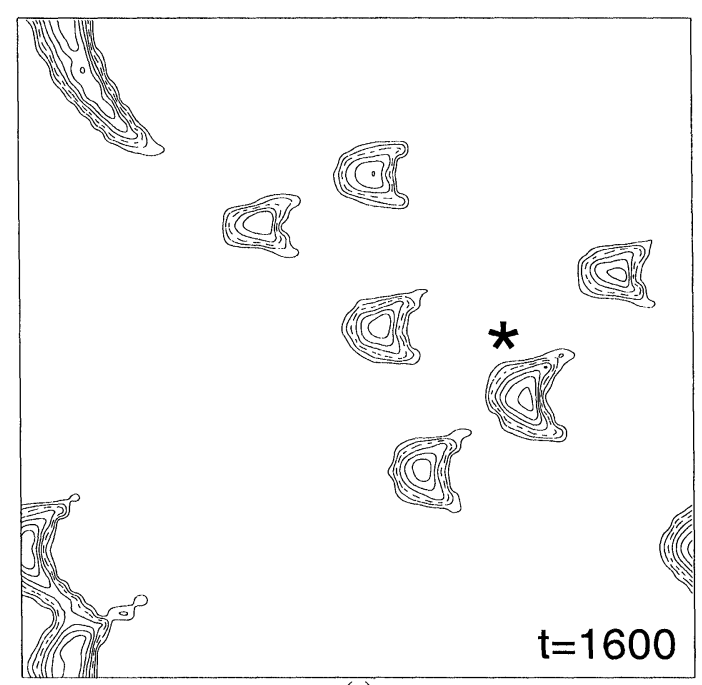

(c)

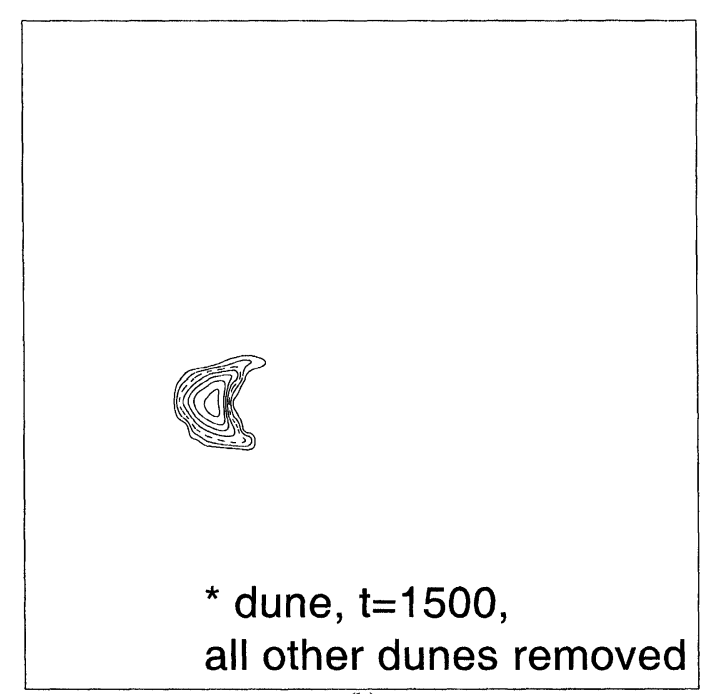

(b)

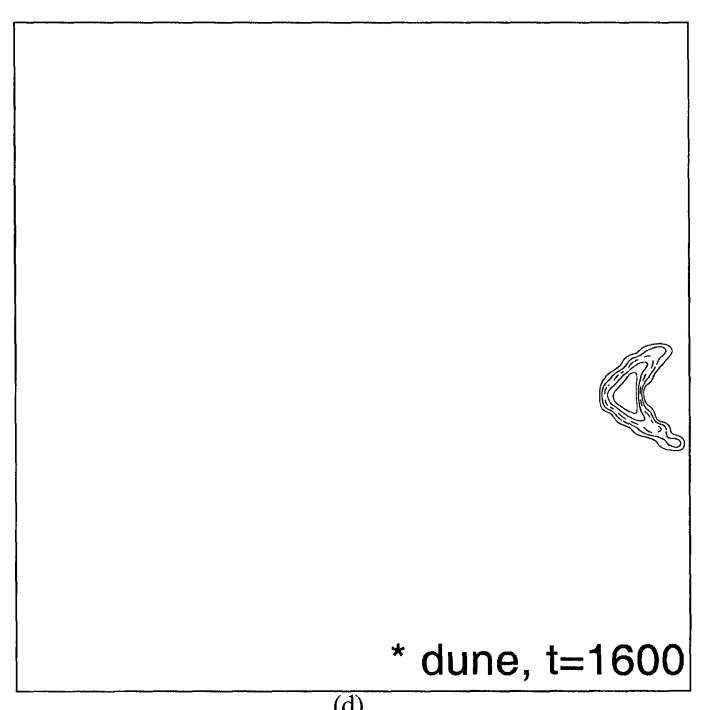

(d)

FIGURE 6 Downwind migration of barchan dunes. (a) Barchan dune field appeared from a almost flat surface after $t=1500$. (b) A selected barchan dune from (a). All others are removed. (c) Barchan dune field of $t=100$ after (a). (d) The barchan dune of $t=100$ after (b).

the relation between the dune type and the formative environment, the latter is comprised of an annual wind directional change and sand availability. Wind direction changes every half a year $(t=2)$. Sand availability and the angle between two directions of wind $\left(h_{\text {avg }}, \theta\right)$ are (a) $\left(100.0,60^{\circ}\right),(\mathrm{b})\left(100.0,120^{\circ}\right),(\mathrm{c})\left(2.0,60^{\circ}\right)$ and (d) $(2.0$, $120^{\circ}$ ). In a dune filed with a limited amount of sand, different types of barchan dunes appear, depending on the angle between two wind directions $(\theta)$. When the angle is $60^{\circ}$, barchan dunes similar to transverse dunes appear, whereas when the angle is $120^{\circ}$, barchan dunes similar to star dunes with three crest lines appear. In a dune field with ample sand, the dune type changes significantly as the angle changes. When the angle is $60^{\circ}$, transverse dunes appear, whereas when the angle is $120^{\circ}$, linear dunes appear. The same transition between transverse dunes and linear dunes associated with wind directional change was also found in the modelling studies of Werner (1995) and
Nishimori et al. (1998) and was theoretically predicted by Rubin and Hunter (1987).

Figure 2 shows the summary of dune types against sand availability and wind directional change. Simulated results are embedded in the empirical diagram compiled by

TABLE IV Dune pattern and the slab transport length $\left(L_{0}\right)$ at the reference height

\begin{tabular}{llcc}
\hline$L_{0}$ & \multicolumn{1}{c}{ Dune pattern } & $h_{\min }$ & $h_{\max }$ \\
\hline 0 & No pattern & 1 & 4 \\
1 & No pattern & 1 & 5 \\
2 & Low transverse dunes & 0 & 7 \\
3 & Barchan dunes & 0 & 34 \\
4 & Barchan dunes & 0 & 40 \\
5 & Barchan dunes & 0 & 40 \\
10 & dome-like barchan dunes & 0 & 31 \\
25 & A few dome dunes & 0 & 15 \\
50 & No pattern & 0 & 8 \\
\hline
\end{tabular}




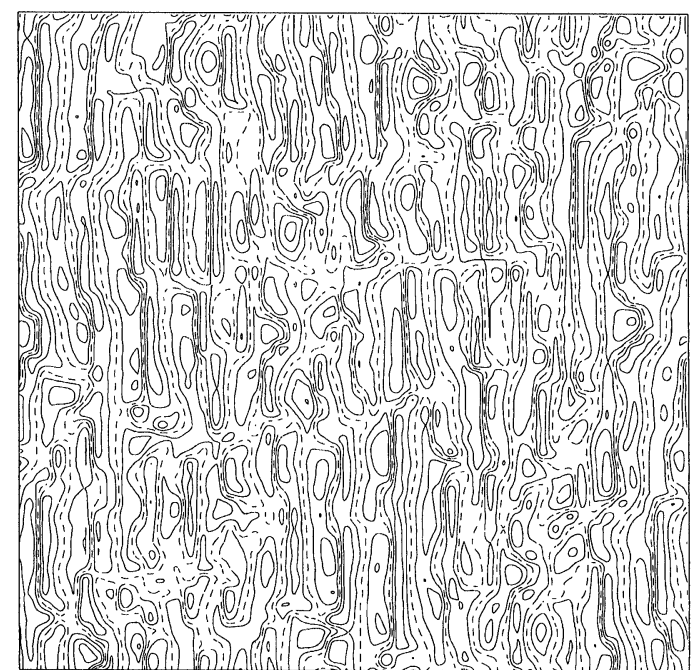

(a)

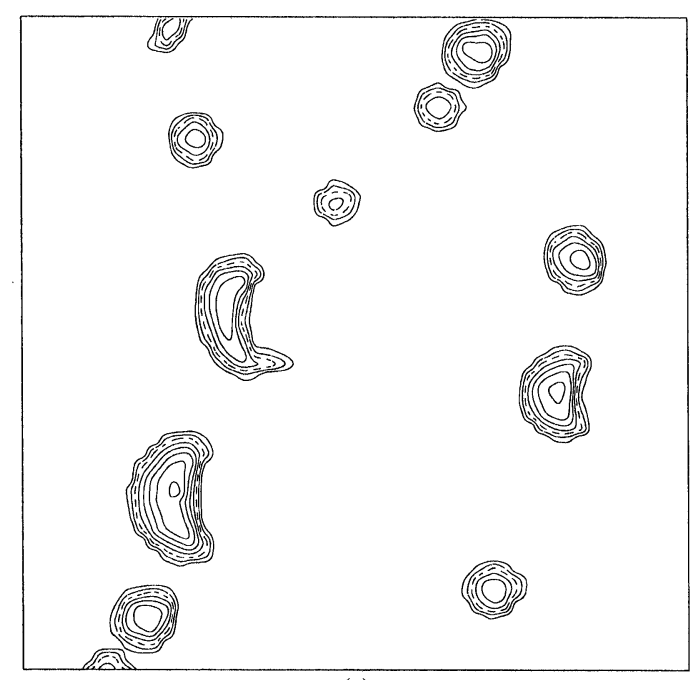

(c)

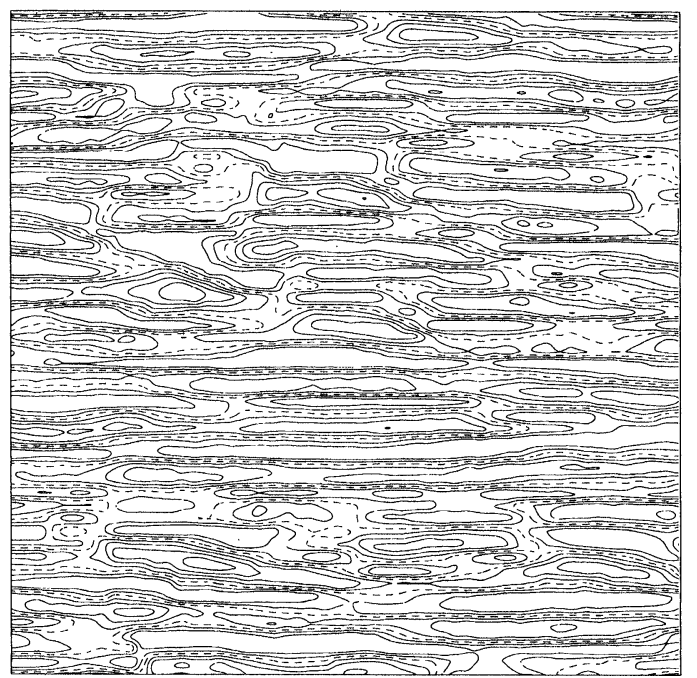

(b)

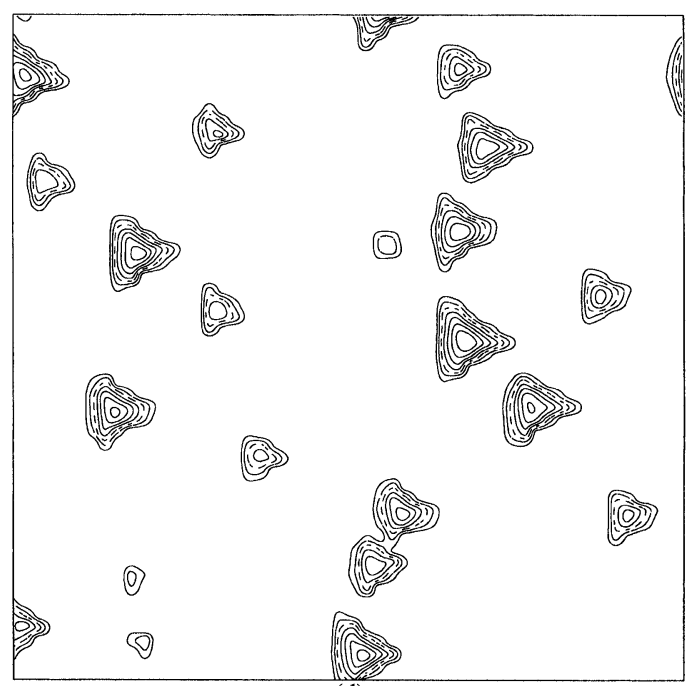

(d)

FIGURE 7 Dune types and wind directional change. Sand availability and angle between two directions of wind $\left(h_{\text {avg }}, \theta\right)$ are (a) $\left(100.0,60^{\circ}\right),(b)$ $\left(100.0,120^{\circ}\right)$, (c) $\left(2.0,60^{\circ}\right)$ and (d) $\left(2.0,120^{\circ}\right)$.

Livingstone and Warren (1996 Figure 5.22). For an infinitely deep sand field, the model correctly matches nature. In a dune field with a limited amount of sand, the simulated results resemble the empirically compiled knowledge, yet more theoretical and field studies are called for especially for strongly bi-directional wind environments.

\section{CONCLUSION}

Building on previous studies, this paper reports development of mathematical models that simulate desert dune fields based on discrete dynamics. Two simplified mechanisms have been employed: the sand transport induced by wind and gravitational shaping. The simulations vividly demonstrate certain aspects of dune fields, and these are consistent with field observations.
Considering the difficulties in calculating wind flow over a complex desert dune field, these simple and phenomenological models are thought to be very promising minimal models. It is shown that by introducing physics-based modifications into the algorithm, dunes more resembling nature are produced.

\section{References}

Anderson, M.G., (Ed.) (1988) Modelling Geomorphological Systems (John Wiley and Sons, Chichester), p 458.

Bagnold, R.A. (1941) The Physics of Blown Sand and Desert Dunes (Methuen, London), p. 265.

Bak, P. (1996) How Nature Works (Springer, New York), p. 212.

Bak, P., Tang, C. and Wiesenfeld, K. (1987) "Self-organised criticality. An explanation of 1/f noise", Physical Review Letters 59, 381-384.

Cooke, R.U., Warren, A. and Goudie, A.S. (1993) Desert Geomorphology (UCL Press, London), p. 526.

de Castro, F. (1995) "Computer simulation of the dynamics of a dune system", Ecological Modelling 78, 205-217. 
Edgett, K.S. and Malin, M.C. (2000) "New views of Mars eolian activity, materials, and surface properties: three vignettes from the Mars Global Surveyor Mars orbital camera", Journal of Geophysical Research 105, 1623-1650.

Frank, A. and Kocurek, G. (1996a) "Toward a model for airflow on the lee side of aeolian dunes", Sedimentology 43, 451-458.

Frank, A.J. and Kocurek, G. (1996b) "Airflow up the stoss slope of sand dunes: limitations of current understanding", Geomorphology 17, 47-54.

Fryberger, S.G. (1979) "Dune forms and wind regime”, In: McKee, E.D., ed, A Study of Global Sand Seas United States Geological Survey, Professional Paper, United States Government Printing Office, Washington, 1052, pp. 137-169.

Greeley, R. and Iversen, J.D. (1985) Wind as a Geological Process on Earth Mars, Venus and Titan (Cambridge University Press, Cambridge), p. 333.

Greeley, R., Arvidson, R.E., Elachi, C., Geriger, M.A., Plaut, J.J., Saunders, R.S., Schubert, G., Stofan, E.R., Thouvenot, E.J.P., Wall, S.D. and Weitz, C.M. (1992) "Aeolian features on Venus: preliminary Magellan results", Journal of Geophysical Research 97, 13319-13345.

Howard, A.D. and Walmsley, J.L. (1985) "Simulation model of isolated dune sculpture by wind", In: Bandorff-Nielsen, O.E., Møller, J.T., Rasmussen, K.R. and Willetts, B.B., eds, Proceedings of International Workshop on the Physics of Blown Sand (University of Aarhus, Aarhus, Denmark), pp 377-391.

Jackson, P.S. and Hunt, J.C.R. (1975) "Turbulent wind flow over a low hill”, Quarterly Journal of the Royal Meteorological Society 101, 929-955.

Kocurek, G., Townsley, M., Yew, E., Havholm, K. and Sweet, M.L. (1992) "Dune and dune-field development on Padre Island, Texas, with implications for interdune deposition and water-table-controlled accumulation", Journal of Sedimentary Petrology 62, 622-635.

Lancaster, N. (1991) "The orientation of dunes with respect to sandtransporting winds: a test of Rubin and Hunter's gross bedformnormal rule", Acta Mechanica Supplement 2, 89-102.

Lancaster, N., Nickling, W.G., McKenna Neuman, C.K. and Wyatt, V.E. (1996) "Sediment flux and airflow on the stoss slope of a barchan dune", Geomorphology 17, 55-62.

Livingstone, I. and Warren, A. (1996) Aeolian Geomorphology (Addison Wesley Longman, Harlow, United Kingdom), p. 211.

McKee, E.D. (1979) "Introduction to a study of global sand seas", In: McKee, E.D., ed, A Study of Global Sand Seas. United States Geological Survey, Professional Paper, 1052, United States Government Printing Office, Washington, pp. 1-19.
Momiji, H. and Warren, A. (2000) "Relations of sand trapping efficiency and migration speed of transverse dunes to wind velocity", Earth Surface Processes and Landforms 25, 1069-1084.

Momiji, H., Carretero-González, R., Bishop, S.R. and Warren, A. (2000) "Simulation of the effect of wind speedup in the formation of transverse dune fields", Earth Surface Processes and Landforms 25, 905-918.

Momiji, H., Bishop, S.R. (2001) Estimating the windward slope profile of a barchan dune. To appear in Sedimentology.

Nishimori, H. and Ouchi, N. (1993) "Formation of ripple patterns and dunes by wind-blown sand", Physical Review Letters 71, 197-200.

Nishimori, H., Yamasaki, M. and Andersen, K.H. (1998) "A simple model for the various pattern dynamics of dunes", International Journal of Modern Physics B12, 257-272.

Pye, K. and Tsoar, H. (1990) Aeolian Sand and Sand Dunes (Unwin Hyman, London), p 396.

Rubin, D.M. and Hunter, R.E. (1987) "Bedform alignment in directionally varying flows", Science $237,276-278$.

Stam, J.M.T. (1997) "On the modelling of two-dimensional aeolian dunes", Sedimentology 44, 127-141.

Van Dijk, P.M., Arens, S.M. and Van Boxel, J.H. (1999) "Aeolian processes across transverse dunes. II: Modelling the sediment transport and profile development", Earth Surface Processes and Landforms 24, 319-333.

Walker, I.J. (1999) "Secondary airflow and sediment transport in the lee of a reversing dune", Earth Surface Processes and Landforms 24, 437-448.

Wasson, R.J. and Hyde, R. (1983) "Factors determining desert dune type", Nature 304, 337-339.

Weng, W.S., Hunt, J.C.R., Carruthers, D.J., Warren, A., Wiggs, G.F.S., Livingstone, I. and Castro, I. (1991) "Air flow and sand transport over sand dunes", Acta Mechanica Supplement 2, 1-22.

Werner, B.T. (1995) "Eolian dunes: computer simulations and attractor interpretation", Geology 23, 1107-1110.

Werner, B.T. (1999) "Complexity in natural landform patterns", Science 284, 102-104.

Wippermann, F.K. and Gross, G. (1985) "The wind-induced shaping and migration of an isolated dune: a numerical experiment", BoundaryLayer Meteorology 36, 319-334.

Woldenberg, M.J., (ed.) (1985) Models in Geomorphology The Binghamton Symposia in Geomorphology: International Series, No. 14., (Allen and Unwin, Boston), p. 434

Zeman, O. and Jensen, N.O. (1988) Progress Report on Modelling Permanent Form Sand Dunes (Ris $\varnothing$ National Laboratory, Roskilde, Denmark) RIS $\emptyset-M-2738$, p. 27. 


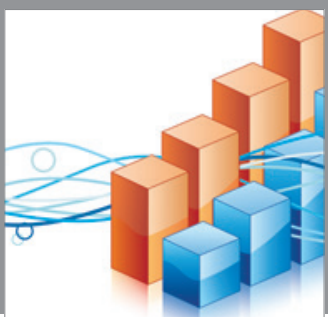

Advances in

Operations Research

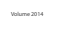

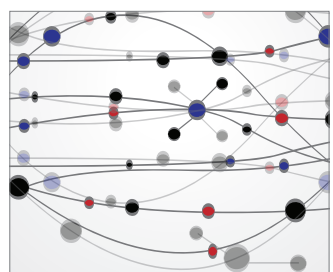

\section{The Scientific} World Journal
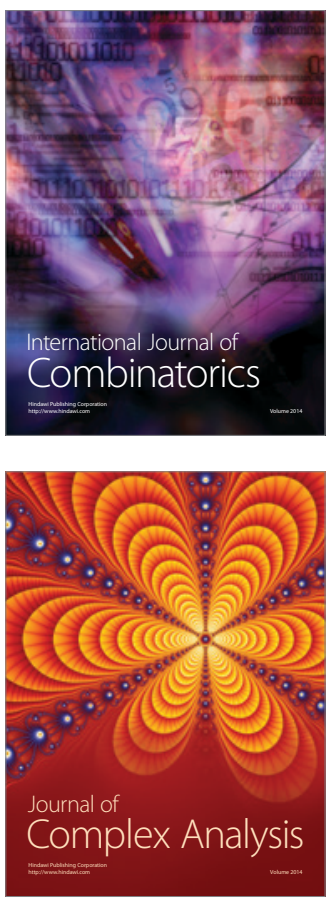

International Journal of

Mathematics and

Mathematical

Sciences
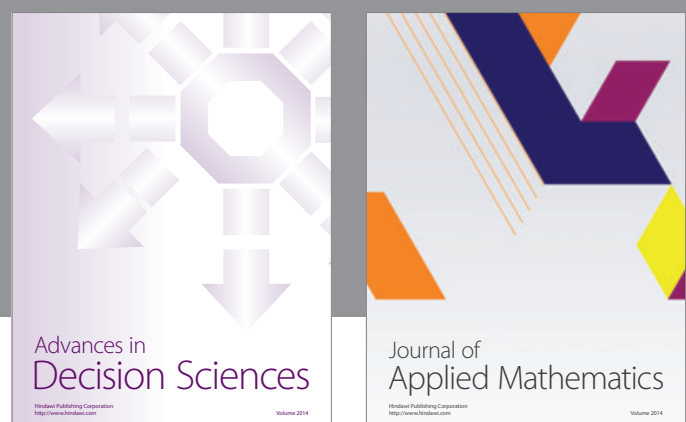

Journal of

Applied Mathematics
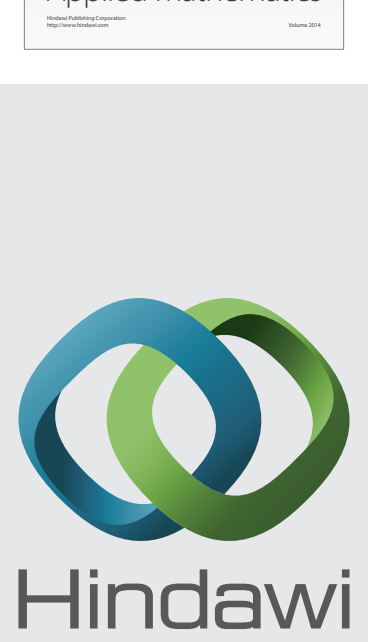

Submit your manuscripts at http://www.hindawi.com
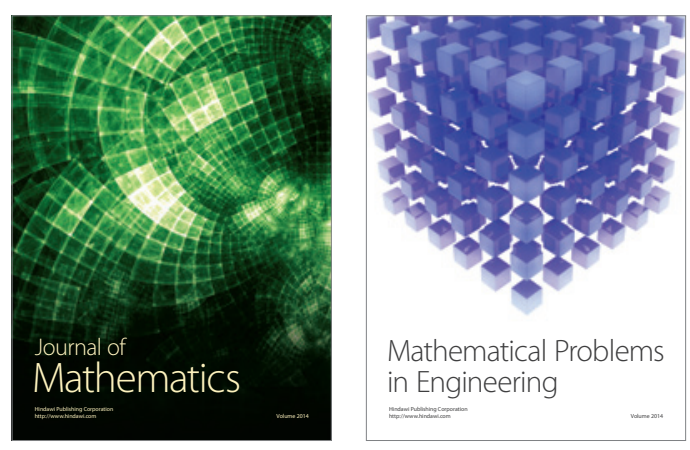

Mathematical Problems in Engineering
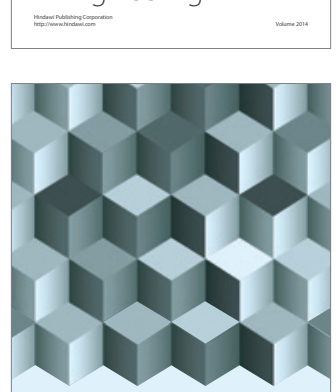

Journal of

Function Spaces
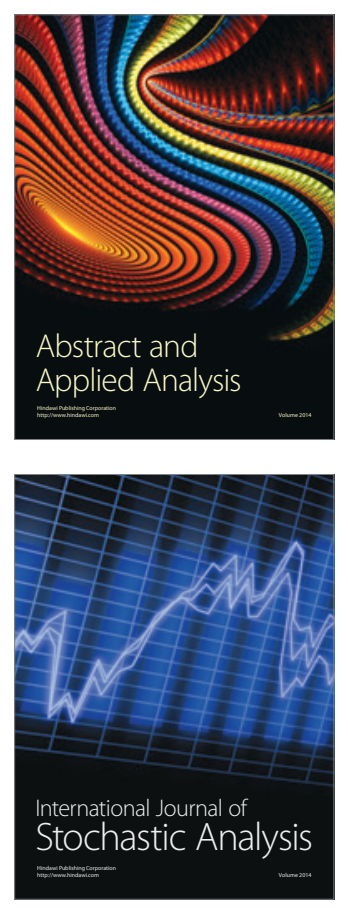

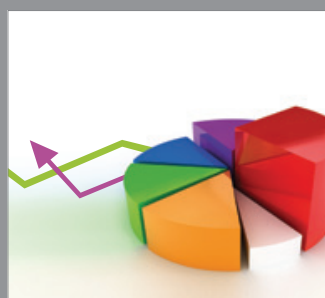

ournal of

Probability and Statistics

Promensencen
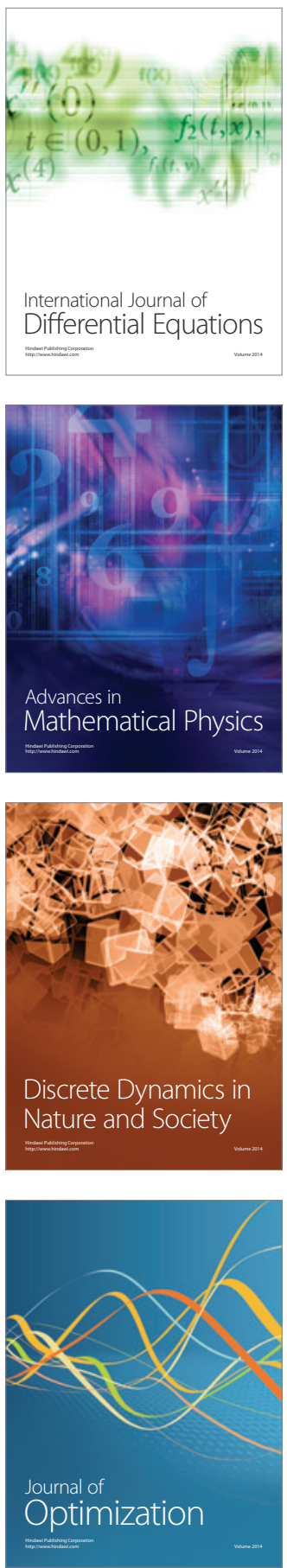